\title{
Rheological Properties of Alumina Injection Feedstocks
}

\author{
Vivian Alexandra Krauss ${ }^{\mathrm{a} *}$, Eduardo Nunes Pires ${ }^{\mathrm{b}}$, Aloísio Nelmo Klein ${ }^{\mathrm{b}}$, Márcio Celso Fredel \\ ${ }^{\mathrm{a} C a m p u s}$ Universitário, Trindade, 88040-360 Florianópolis - SC, Brazil \\ bLaboratório de Materiais, Programa de Pós-Graduação em Engenharia Mecânica - POSMEC, \\ Departamento de Engenharia Mecânica, Universidade Federal de Santa Catarina - SC, Brazil
}

Received: November 23, 2003; Revised: March 19, 2005

\begin{abstract}
The rheological behavior of alumina molding feedstocks containing polyethylene glycol (PEG), polyvinylbutyral (PVB) and stearic acid (SA) and having different powder loads were analyzed using a capillary rheometer. Some of the feedstocks showed a pseudoplastic behavior of $n<0$, which can lead to the appearance of weld lines on molded parts. Their viscosity also displayed a strong dependence on the shear rate. The slip phenomenon, which can cause an unsteady front flow, was also observed. The results indicate that the feedstock containing a lower powder load displayed the best rheological behavior. The 55 vol. \% powder loaded feedstock presented the best rheological behavior, thus appearing to be more suitable than the formulation containing a vol. $59 \%$ powder load, which attained viscosities exceeding $10^{3} \mathrm{~Pa}$.s at low shear rates, indicating its unsuitability for injection molding.
\end{abstract}

Keywords: alumina, rheological behavior, ceramic injection molding

\section{Introduction}

Powder Injection Molding (PIM) is cost effective in the high volume production of small, complex, precision parts. The PIM process evolved from the traditional shape-making capability of plastic injection molding and the flexibility of materials employed in powder metallurgy. The process involves several steps ranging from mixing to sintering, but the production of reliable shapes requires correct injection molding conditions. The powder is blended with an organic vehicle in order to take advantage of the injection molding route. The binder system usually has three components - a backbone polymer that provides strength, a filler phase that is easily extracted in the first phase of debinding, and a surfactant serving as a bridge between the binder and powder ${ }^{1}$.

In a study of a variety of thermoplastic binder systems ${ }^{2}$ (ceramic powder-polymer suspensions), it was concluded that such systems should possess three flow characteristics: a flow index $(n)$ lower than one (power law), fluidity greater than $10 \mathrm{~Pa} . \mathrm{s}$ at a shear rate $(\dot{y})$ of about $100 \mathrm{~s}^{-1}$, and a relatively low dependence of the viscosity $(\mathrm{H})$ on temperature at the same shear rate. Furthermore, shrinkage in the binder system resulting from to phase changes or thermal contraction should be kept to a minimum. Equation 1 shows the power law, where $\mathrm{k}$ is a consistency factor:

$$
\eta=k \dot{y}^{n-1}
$$

The rheological properties are important in the injection molding step, since they involve the flow of the feedstock during that step. Rheological analyses can be made to quantify the stability of the feedstock during the molding process.

This study focused on the characterization of the flow properties of formulations based on a polymer and a low molecular weight component plus a surfactant, the final goal being to identify a suitable feedstock for use in injection molding.

\section{Experimental}

\subsection{Materials}

Alumina powder of commercial purity (Alcoa, A1000SG) was used in this study. The particle morphology and a typical size distri- bution are shown in Figures 1 and 2. The specific surface area was $9.3 \times 10^{3} \mathrm{~m}^{2} / \mathrm{kg}$ according to the manufacturer.

A multi-component binder system was used to prepare the alumina feedstock. Table 1 lists the binders used in the experiments.

\subsection{Compounding}

Formulations containing 55 to $59 \%$ in volume of powder were prepared in order to study the effect of solid loads on the rheological behavior of alumina injection molding feedstocks.

The remaining volume consisted of the aforementioned binders, whose volume ratio was PEG:PVB 2:1 and $\mathrm{Al}_{2} \mathrm{O}_{3}:$ SA 25:1.

Table 2 illustrates the composition of the feedstocks used in this study. The alumina powder was dried before mixing in an oven at $110{ }^{\circ} \mathrm{C}$ for 1 hour. Five feedstocks were prepared with the help of a sigma-type blade mixer (Haake Polylab System) having a rotation frequency of $90 \mathrm{rpm}$. All the components of the feedstock were added simultaneously at $180{ }^{\circ} \mathrm{C}$ for 30 minutes. Granules were obtained and mixed a second time at $160{ }^{\circ} \mathrm{C}$ for 30 minutes to produce a homogenized feedstock, as recommended in the literature ${ }^{3}$.

\subsection{Rheology}

The viscosity of the formulations was measured using a capillary rheometer (Haake 3000p) after each mixing experiment. The pressure drop across the length of the die $(L / D=30)$ was measured with a pressure transducer placed adjacent to the die entrance.

The rheometer's piston speed was varied to obtain different shear rates and the corresponding pressure drops were measured to calculate the shear stress. The apparent viscosity is given by the shear stress divided by the shear rate.

\section{Results and Discussion}

Figures 3 and 4 show the torque $v s$. time and density of processed feedstocks $v s$. powder loads.

Torque is a measure of the resistance on the rotor blades. The mixing torque value indicates the degree of homogeneity. Feedstocks 
that show lower torque values are better mixed than those with high values ${ }^{4}$. The friction is created with higher powder loads; therefore, the resistance on the rotor blades is higher ${ }^{5}$.

Typically, it was observed that higher powder loads resulted in a higher torque level at the end of mixing the process. The $55 \%$ volume solid load exhibited the lowest torque, as expected. Other feedstocks presented the same torque level.

Figure 4 indicates that feedstock density is directly dependent on the powder loading volume; in other words, the higher the powder load, the higher the feedstock's density.

Figures $5 \mathrm{a}, \mathrm{b}$ and $\mathrm{c}$ show the viscosity $v s$. shear rate curve for three different temperatures for F55, F57 and F59.

The feedstocks exhibited a pseudoplastic flow behavior and the viscosity decreased as the shear rate increased at all working temperatures, as indicated in Figure 5. F55 showed a critical shear rate value, at which point its viscosity dropped dramatically. This phenomenon will be discussed later.

The declining viscosity with rising shear rates indicates particle (or binder molecule) orientation with flow, likely indicating and improving the material's homogeneity. In addition, for ceramic injection molding, the shear rates can vary from 100 to $1000 \mathrm{~s}^{-1}$ and the flow rate during injection molding requires a viscosity of less than 1000 Pa.s ${ }^{1}$. For this reason, F59 is not recommended for use in the injection molding process.

Table 1. Characteristcs of binders used in this study.

\begin{tabular}{lrlc}
\hline \multicolumn{1}{c}{ Binder } & $\begin{array}{c}\text { Molecular } \\
\text { Weight }\end{array}$ & Supplier & $\begin{array}{c}\text { Pycnometer } \\
\text { density }\left(\mathrm{kg} / \mathrm{m}^{3}\right)\end{array}$ \\
\hline $\begin{array}{l}\text { Stearic Acid(SA) } \\
\text { Polyethylene } \\
\text { glycol(PEG) }\end{array}$ & 284 & Vetec & 940 \\
$\begin{array}{l}\text { Polyvinylbutyral } \\
\text { (PVB) }\end{array}$ & 6000 & Oxiteno & 1220 \\
\hline
\end{tabular}

Table 2. Composition of feedstocks.

\begin{tabular}{cccccc}
\hline $\begin{array}{c}\text { Feedstocks } \\
\text { Solids loading, } \\
\text { vol. (\%) }\end{array}$ & $\mathrm{Al}_{2} \mathrm{O}_{3}$ & PEG & PVB & SA & $\begin{array}{c}\text { Feedstock } \\
\text { abbreviation }\end{array}$ \\
\hline 55 & 80.55 & 12.81 & 5.88 & 0.76 & F55 \\
56 & 81.18 & 12.37 & 5.68 & 0.77 & F56 \\
57 & 81.80 & 11.94 & 5.48 & 0.77 & F57 \\
58 & 82.41 & 11.52 & 5.29 & 0.78 & F58 \\
59 & 83.01 & 11.11 & 5.10 & 0.78 & F59 \\
\hline
\end{tabular}

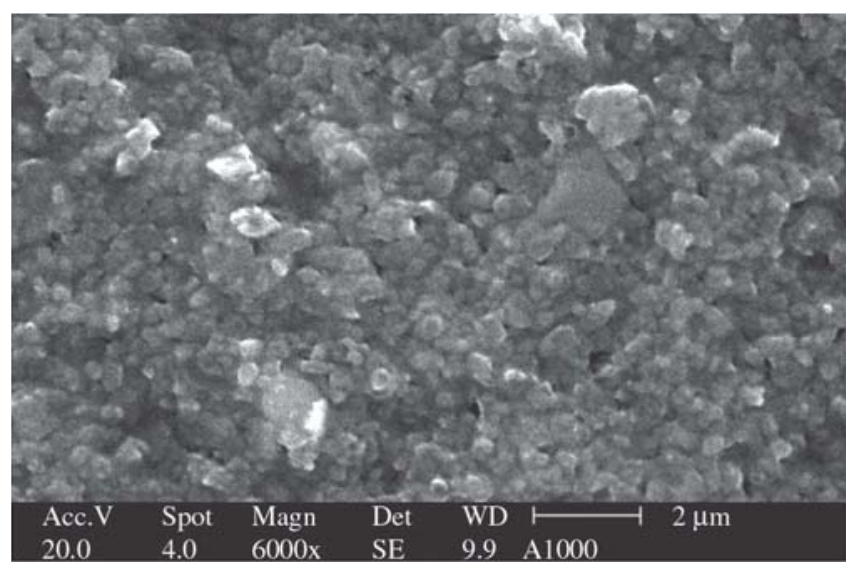

Figure 1. Scanning electron micrograph of alumina.
As the temperature rose, feedstock's viscosity declined slightly within the temperature range tested here.

This phenomenon is due mainly to (a) a reduction of the powder volume resulting from greater expansion of the binder when heat is

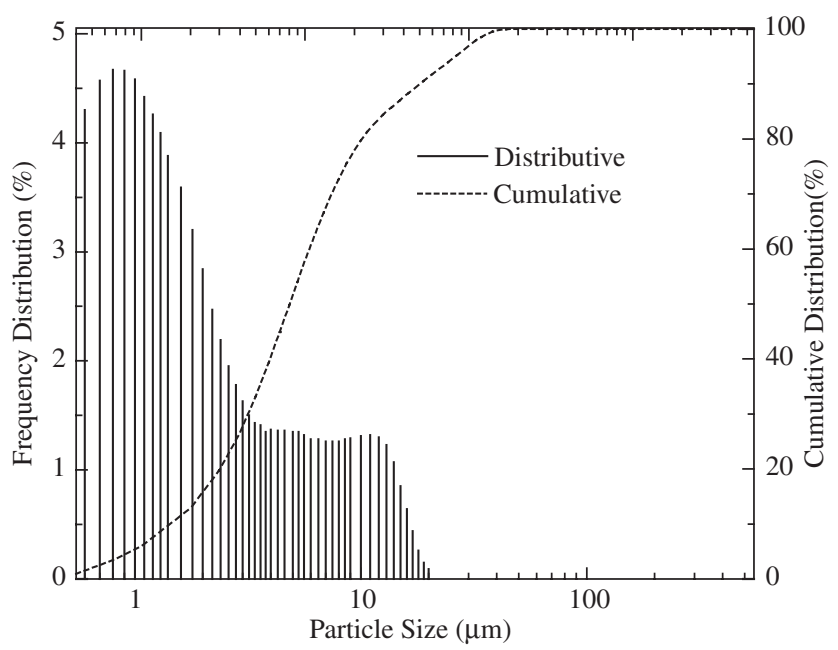

Figure 2. Particle size distribution of alumina.

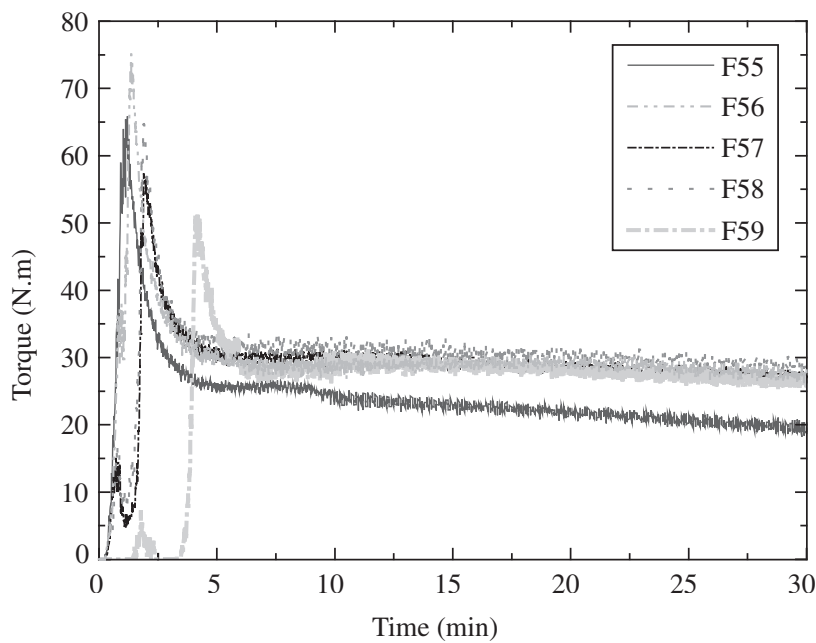

Figure 3. Mixing behavior for different volumetric powder loads.

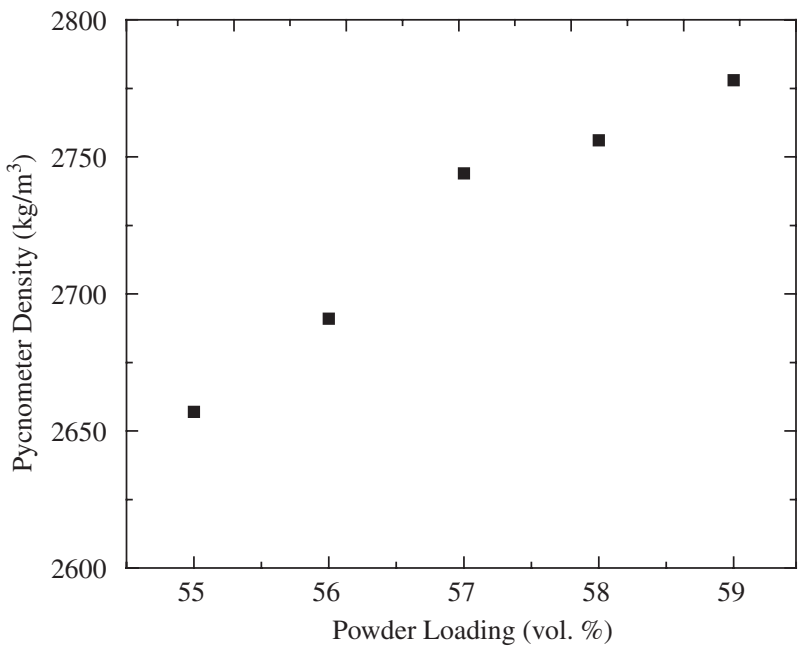

Figure 4. Feedstocks densities. 


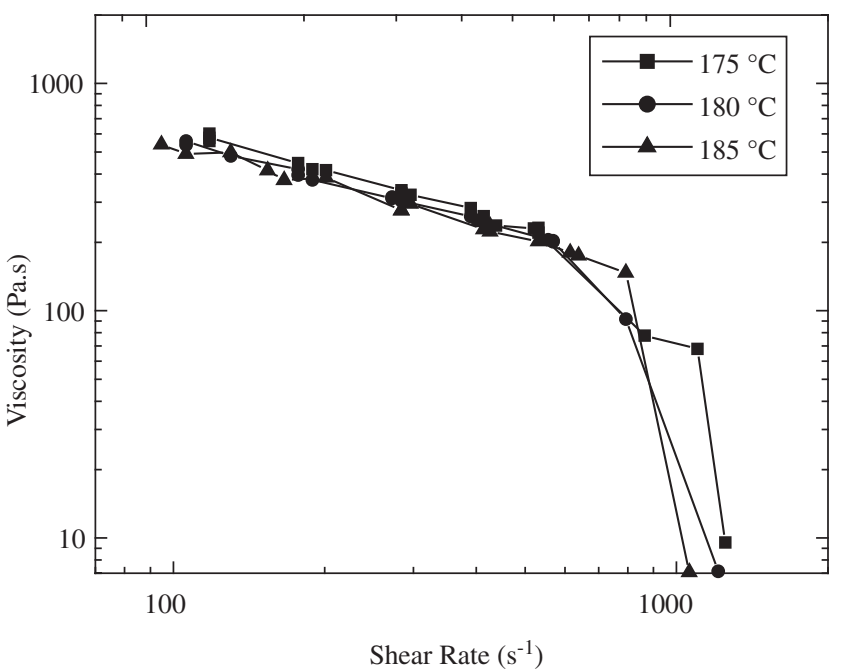

(a)

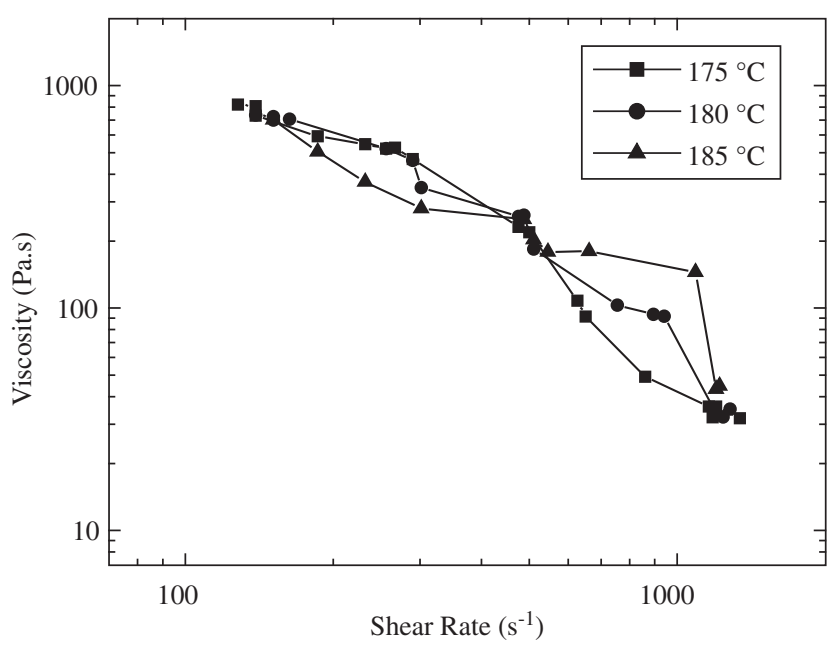

(b)

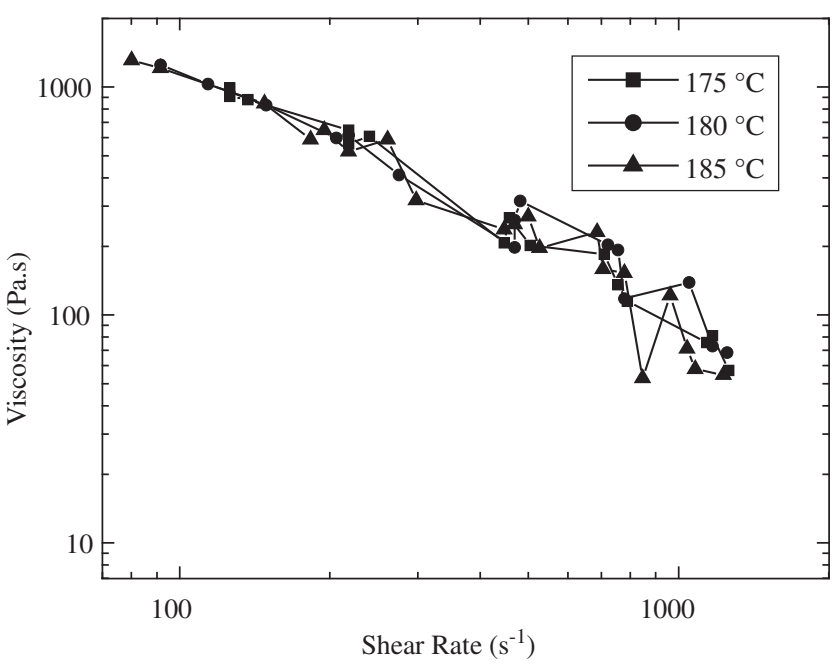

(c)

Figure 5. Viscosity $v s$. shear rate graphs of different formulation: a) F55; b) F57; c) F59. applied, and (b) disentanglement of the molecular chain when more heat is distributed to fluctuate the random molecular structure ${ }^{1}$.

Figure 6 shows the rheological behavior of feedstocks at $175^{\circ} \mathrm{C}$.

Figure 6 indicates that, at a low shear rate, the viscosity curve for five powder volume formulations differed. The viscosity values of F57, F58 and F59 began to become more unstable from $500 \mathrm{~s}^{-1}$ up in response to an oscillating flow which occurred during the experiment.

Table 3 lists the flow behavior index $n$ assessed based on the viscosity $v s$. shear rate plot at the nozzle temperature. The data obtained at shear rates above $900 \mathrm{~s}^{-1}$ were not included for the $n$ evaluation.

Table 3 shows that an increasing powder load led to a dramatic drop in the $n$ value. Had the data above $900 \mathrm{~s}^{-1}$ been considered, all the $n$ values would have been negative.

Although the various compositions received only slightly different amounts of solid loads, this difference caused F55 to display an anomalous behavior in comparison with the other feedstocks. This behavior might have resulted from F55 reaching close to the critical value of solids loading.

Critical solids loading is reached when the particles rub against each another, causing the mixture to become free of voids, at which point the viscosity is very high. Critical loading is reached when the particles in the composition are packed together as tightly as possible without external pressure and all spaces between the particles are filled with binder. Departures from the ideal behavior result from deficiencies in the binder content and formation of voids. Capillary forces resist void formation by pulling the particles together, increasing the friction to the point where the viscosity is unacceptably high. As the powder to binder ratio increases, the viscosity becomes essentially infinite at the critical solids loading point. Small errors in formulating

Table 3. Flow behavior index $n$

\begin{tabular}{cccc}
\hline Formulation & $175^{\circ} \mathrm{C}$ & $180{ }^{\circ} \mathrm{C}$ & $185^{\circ} \mathrm{C}$ \\
\hline F55 & 0.37 & 0.41 & 0.40 \\
F56 & 0.27 & 0.12 & 0.13 \\
F57 & $*$ & $*$ & $*$ \\
F58 & $*$ & $*$ & $*$ \\
F59 & $*$ & 0.02 & $*$ \\
\hline
\end{tabular}

$* \mathrm{n}<0$

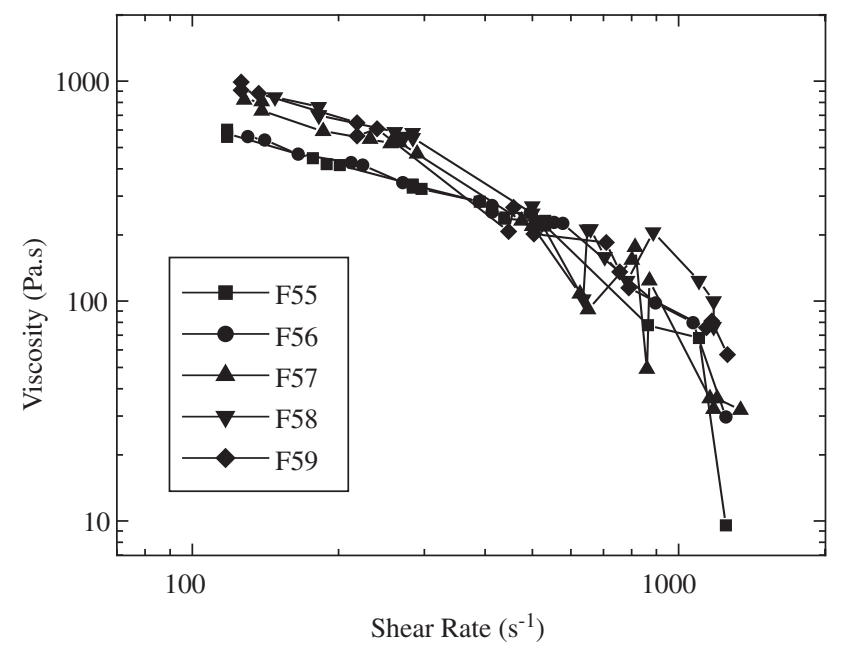

Figure 6. Feedstock viscosity vs. shear rate at $175^{\circ} \mathrm{C}$. 
a feedstock cause molding sensitivities because of rapid viscosity changes in solids loading. Since the viscosity of a mixture changes most rapidly when a composition approaches the critical loading point, small errors are amplified into large viscosity shifts ${ }^{1}$.

The exponent $n$ of the power law index indicates the shear sensitivity. A lower $n$ of the feedstock indicates a higher shear sensitivity and greater pseudoplastic behavior of the feedstocks. Some molding defects such as jetting are associated with low $n$, i.e., higher shear sensitivity. Jetting occurs when the melt does not adhere to the walls as it emerges from the gate and enters the mold. Instead, the melt moves in a narrow 'stream' having approximately the width of the gate. Jetting is undesirable since it is the source of severe defects, including weld lines and other imperfections in the final molded part. When $n=0$, the no-slip condition at the wall is not valid and the material flows as a solid. Solid-phase jetting occurs when wallslip takes place. Therefore, the value of $n$ can be used to predict the liquid-solid phase transition ${ }^{6}$. That considered, F55 displayed the best rheological behavior and, of all the formulations tested here, is the one that should be processed. The other formulations did not possess the necessary characteristics for injection molding.

An earlier study ${ }^{7}$ reported similar results of apparent viscosity versus shear stress, indicated by three clear behavior regions in the graph. The behavior was typical of slip flow. The first portion of the apparent viscosity $v s$. shear stress curve represented flow due to shear at a lower shear stress. The decline in apparent viscosity with increasing shear stress represented the behavior in which a thin layer of liquid was formed and the paste flowed as a plug. There was a clearly defined transition region in the graph, defined by a critical wall shear stress that can be exceeded during the extrusion or injection molding of ceramic pastes, leading to a condition of slip flow.

It is essential that feedstocks present a steady front flow.

In the case of steady flow, the pressure at a particular shear rate quickly reaches a stable value. The pressure-time of an unstable formulation shows the phenomenon of "oscillating flow" at high shear rates. Here the pressure oscillates widely during slip-stick flow through the die rather than showing a constant pressure trace. Similar observations have been reported for unfilled polymers and attributed to slippage (non-zero velocity of the fluid at the solid-liquid interface ${ }^{8}$ ) of the melt on the capillary wall ${ }^{9}$.

This phenomenon, which depends on both temperature and shear rate, is responsible for the unsteady front flow observed during injection molding. Hence, wall slip can be correlated with the presence of injection flaws. The fact that the extrudate emerged from the die at variable rates suggests that a similar effect would be in operation during injection molding. This kind of flow pattern could give rise to weld lines in the moldings, which create planes of weakness ${ }^{10}$.

Some of the results obtained in this work indicated the presence of wall slip at high shear rates. The pressure-time behavior of all the formulations tested here, with the exception of F55, presented an oscillating flow at shear rates of more than $300 \mathrm{~s}^{-1}$. This behavior is one more indication that F55 is the most suitable choice for injection molding.

These problems can be solved by adopting several procedures. First, there is the opportunity of a choice. In this case, F55 can be chosen as the most suitable of the five formulations tested. Second, some changes in the components can be made to improve the characteristics of injection molding feedstocks, such as using powders with bimodal distribution or using other additives for injection molding.

\section{Conclusions}

The results of this work revealed the pseudoplastic behavior of the feedstocks. Clearly, the higher the solid loading the lower the flow index behavior $n$ value that leads to the slip flow phenomenon, which can cause molding defects. The temperature dependence of viscosity was not evidenced within the tested range. On this basis, the formulation with $55 \%$ vol. powder loading showed the best rheological behavior.

\section{Acknowledgments}

Vivian Alexandra Krauss is grateful for the financial support provided by CNPq (Brazil).

\section{References}

1. German RM, Bose A. Injection molding of metals and ceramics. Princeton: Metal Powder Industries Federation; 1997.

2. Edirisinghe MJ, Evans JR. Systematic development of the ceramic injection moulding process. Materials Science and Engineering A. 1989; 109: 17-26.

3. Harima E. Estudo da moldagem de pós de alumina por injeção com ênfase na formulação e remoção de ligante. D. Phil thesis. Florianópolis: Universidade Federal de Santa Catarina; 2003.

4. White GR, German RM. Dimensional control of powder injection molded 3161 stainless steel using in situ molding correction. In: Advances in Powder Metallurgy \& Particulate Materials. 5: Powder Injection Molding. Princeton: Metal Powder Industries Federation; 1993. p. 121-132.

5. Supati R, Loh NH, Tor SB. Mixing and characterization of feedstock for powder injection molding. Materials Letter. 2000; 46(2): 109-196.

6. Piccirillo N, Lee D. Jetting phenomenon in powder injection molding. The International Journal of Powder Metallurgy. 1992; 28(1): 13-25.

7. Huzzard RJ, Blackburn S. Slip flow in concentrated alumina suspensions. Powder Technology. 1998; 97(2): 118-123.

8. Brydson JA. Flow properties of polymer melts. London: Godwin; 1981.

9. Edirisinghe MJ, Evans JR. Rheology of ceramic injection moulding formulations. Ceramic Transactions Journal. 1987; 86: 18-22.

10. Dubus M, Burlet H. Rheological behavior of a polymer ceramic blend. Journal of the European Ceramic Society. 1997; 17(2): 191-196. 